\title{
Giant Hypertrophic Gastritis and Acute Hepatitis Associated with Cytomegalovirus Infection
}

\author{
Yuichi Nakazato, Soichiro Toyorzumi*, Fumio Kinoshita, Hitoshi Sugiura**, Hisami Iri** \\ and Kenji Окиво
}

\begin{abstract}
A 38-year-old man developed prominent hypoproteinemia after acute elevation of serum transaminase levels. Giant hypertrophy of the gastric mucosa, a short serum albumin half-life, and the absence of massive hepatocyte necrosis established the diagnosis of protein-losing gastropathy. The hypoproteinemia, gastric fold hypertrophy and hepatitis remitted spontaneously within 4 months. A high antibody titer against cytomegalovirus suggested an association between the viral infection and the patient's disease.
\end{abstract}

(Internal Medicine 31: 816-819, 1992)

Key words: Ménétrier's disease, protein-losing gastropathy

\section{Introduction}

Protein-losing gastropathy characterized by giant hypertrophy of the gastric folds was first described by Ménétrier in 1988 (1). The disease usually has a chronic course; spontaneous remission has been documented in only a few cases. We report a case of acute hepatitis in which giant hypertrophic gastritis and severe hypoproteinemia were observed transiently during the course of the disease.

\section{Case Report}

A 38-year-old Japanese male presented with a 3-week history of sore throat and low-grade fever on September 11, 1990. The patient complained of poor appetite and fatigue but denied epigastric pain. Oral antibiotics prescribed at a clinic had failed to improve his symptoms. Blood chemistry studies revealed a GOT of $50 \mathrm{U} / 1$, GPT of $56 \mathrm{U} / 1$, and $\mathrm{LDH}$ of $646 \mathrm{U} / 1$. Fever $\left(37.0-37.6^{\circ} \mathrm{C}\right)$ and anorexia remained unchanged, and laboratory studies repeated a week later revealed further elevation of GOT, GPT, and LDH. The patient was admitted to our hospital on September 20 for probable acute hepatitis. He had a history of transient proteinuria in his childhood, herpes zoster at age 20, and tonsillectomy for recurrent tonsillitis at age 34 . His family history was unremarkable.

On admission the patient's temperature was $37.2^{\circ} \mathrm{C}$.
He was well-developed and well-nourished and had no peripheral edema. No lymphadenopathy or skin rash was observed. There was tenderness on percussion around the right costal margin, but no hepatomegaly or splenomegaly was detected. Shortly after admission, several enlarged cervical lymph nodes became palpable bilaterally, and the liver also became palpable about $2 \mathrm{~cm}$ below the right costal margin. Both the lymphadenopathy and hepatomegaly became undetectable one week later.

Laboratory data on admission (Table 1) showed lymphocytosis (WBC $10.5 \times 10^{3} \mu \mathrm{l}$, lymphocytes $72 \%$, atypical lymphocytes $1 \%$ ) and mild thrombocytopenia $\left(10.9 \times 10^{4} / \mu \mathrm{l}\right)$. Urinalysis, electrolytes, creatinine, alkaline phosphatase, and total bilirubin were normal, but GOT was $405 \mathrm{U} / 1$, GPT $597 \mathrm{U} / 1$, and LDH 1,220 U/1. Mild hypoproteinemia $(6.0 \mathrm{~g} / \mathrm{dl})$ was noted, but the $\mathrm{A} / \mathrm{G}$ ratio and the serum protein electrophoretic pattern were normal. The RA test was weakly positive. Serum immunoglobulin, C3, and C4 levels revealed no remarkable changes. Serological tests failed to detect hepatitis $\mathrm{A}, \mathrm{B}$, or $\mathrm{C}$ antigens or antibodies. The serum complement fixation (CF) antibody titer against cytomegalovirus (CMV) was 1:256, and a slight elevation of antibody titers against $\mathrm{EB}$ virus VCA (IgG, fluorescence antibody method) and Toxoplasma (passive hemaglutination) was also observed.

Despite the transient appearance of lymphadenopathy

From the Department of Internal Medicine, *the Department of Surgery, Fussa Hospital, Fussa and **the Division of Pathology, Central Clinical Laboratories, Keio University Hospital, Tokyo

Received for publication October 7 1991; Accepted for publication February 26, 1992

Reprint requests should be addressed to Dr. Yuichi Nakazato, the Department of Internal Medicine, Saitama-Chuo Hospital, 4-9-3 Kitaurawa, Urawa 336, Japan 


\section{Hepatitis with Protein-losing Gastritis}

Table 1. Laboratory Findings on Admission

\begin{tabular}{lclc}
\hline Peripheral blood & & Urinalysis & \\
RBC & $423 \times 10^{4} / \mu \mathrm{l}$ & protein & $( \pm)$ \\
Hb & $14.2 \mathrm{~g} / \mathrm{dl}$ & sugar & $(-)$ \\
Platelet & $10.9 \times 10^{4} / \mu \mathrm{l}$ & sediment & normal \\
WBC & $10.5 \times 10^{3} / \mu \mathrm{l}$ & & \\
$\quad$ Baso & $1 \%$ & Stool examination & $(-)$ \\
Eosino & $0 \%$ & occult blood & \\
Staph & $7 \%$ & & Immunology/Serology \\
Seg & $14 \%$ & IgG & $1,370 \mathrm{mg} / \mathrm{dl}$ \\
Lymph & $72 \%$ & IgA & $273 \mathrm{mg} / \mathrm{dl}$ \\
Atypical lymph & $1 \%$ & IgM & $392 \mathrm{mg} / \mathrm{dl}$ \\
Mono & $5 \%$ & C3 & $70 \mathrm{mg} / \mathrm{dl}$ \\
& & C4 & $38 \mathrm{mg} / \mathrm{dl}$ \\
Blood coagulation & $37 \mathrm{~s}(\mathrm{nl}=25-40)$ & ASO & $50 \mathrm{mg} / \mathrm{dl}$ \\
APTT & $76 \%(\mathrm{nl}=70-130)$ & RA test & $(+)$ \\
PT & & anti-HA & $(-)$ \\
& & HBs Ag & $(-)$ \\
Blood chemistry & $0.4 \mathrm{mg} / \mathrm{dl}$ & anti-HBs & $(-)$ \\
TB & $405 \mathrm{U} / 1$ & anti-HC & $(-)$ \\
GOT & $597 \mathrm{U} / 1$ & anti-Cytomegalovirus $(\mathrm{CF})$ & $1: 256(\mathrm{nl}<1: 4)$ \\
GPT & $1,220 \mathrm{U} / 1$ & anti-EB-VCA IgG & $1: 640(\mathrm{nl}<1: 10)$ \\
LDH & $10.0 \mathrm{U} / 1$ & anti-EB-VCA IgM & $1: 10(\mathrm{nl}<1: 10)$ \\
A1-P & $70 \mathrm{U} / 1$ & anti-Toxoplasma $(\mathrm{PHA})$ & $1: 512(\mathrm{nl}<1: 128)$ \\
LAP & $6.0 \mathrm{~g} / \mathrm{dl}$ & anti-Mycoplasma $(\mathrm{PA})$ & $<1: 40(\mathrm{nl}<1: 40)$ \\
TP & 1.29 & & \\
A/G & $137 \mathrm{mg} / \mathrm{dl}$ & & \\
TCh & & & \\
\hline
\end{tabular}

$\mathrm{nl}$ : normal value

and hepatomegaly, transaminase values and symptoms (low-grade fever, sore throat, and anorexia) rapidly improved after admission (Fig. 1). As serum transaminase values improved, however, serum protein levels decreased. At the end of one month total protein and albumin had dropped to $3.8 \mathrm{~g} / \mathrm{dl}$ and $2.0 \mathrm{~g} / \mathrm{dl}$, respectively. There was no edema, gastrointestinal symptoms, or neurological abnormalities. Repeated urinalysis and blood coagulation test were normal. To further rule out the possibility of liver failure, a liver biopsy was per-

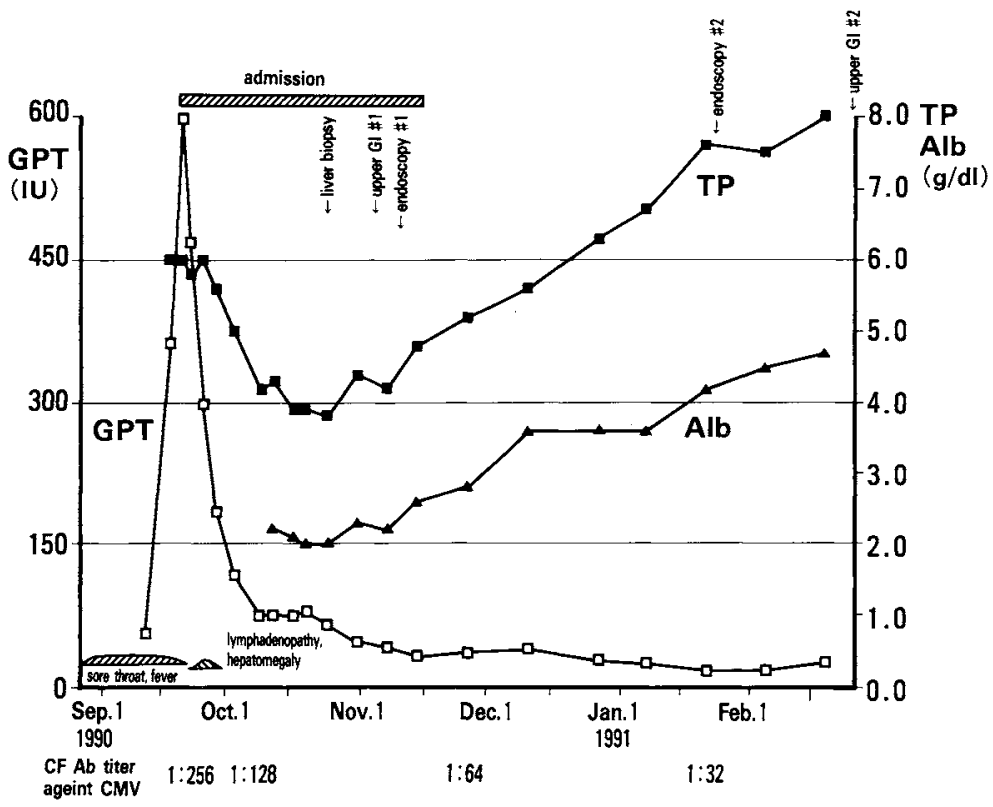

Fig. 1. Clinical course. The patient was hospitalized from Sept. 20 to Nov. 16, 1990. The serum levels of total protein (TP, - - ) albumin (Alb, - - -), and glutamic pyruvic transaminase (GPT, $-\square-)$ ) are shown. The CF antibody titer against cytomegalovirus (CMV) is included at the bottom of the figure. 

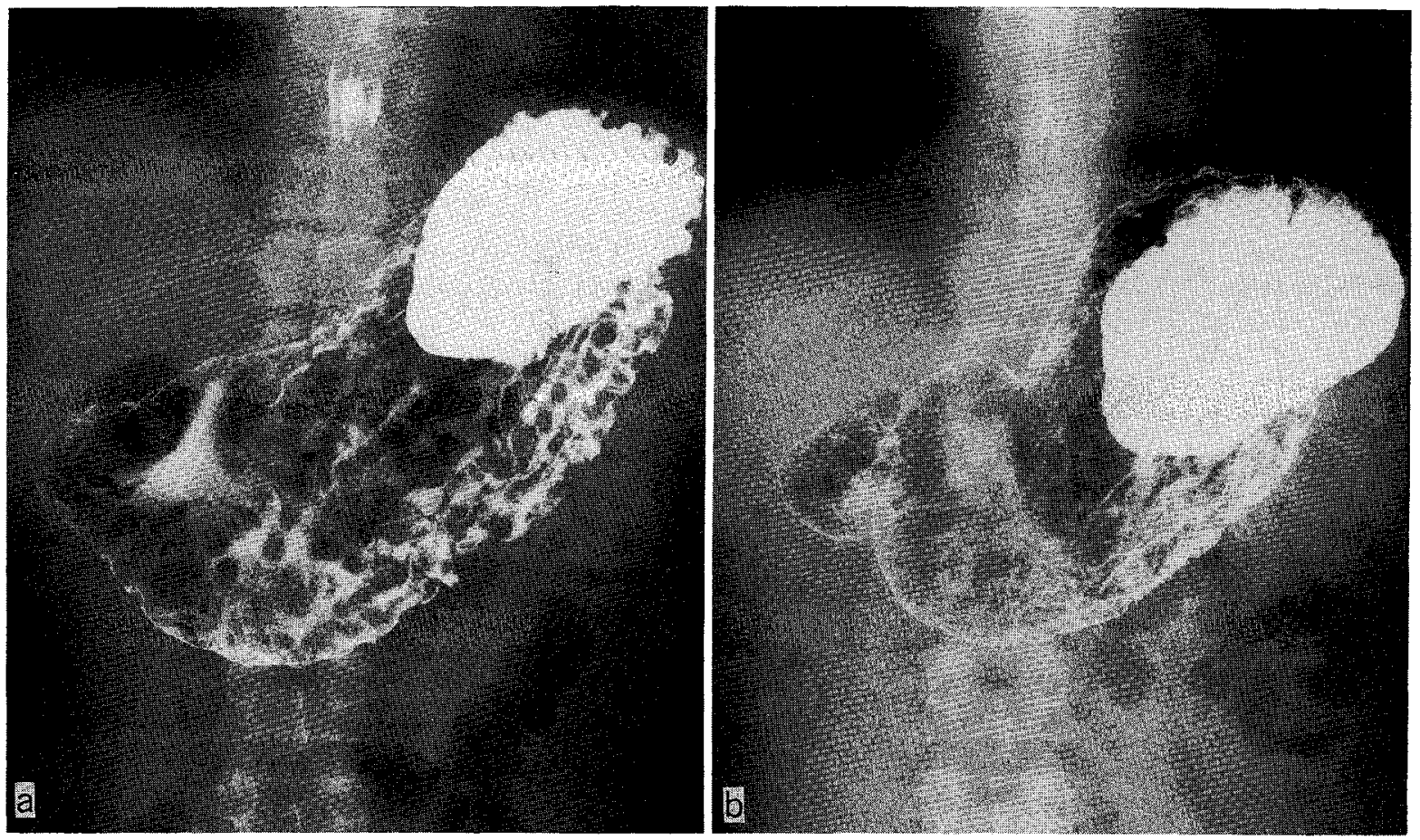

Fig. 2. X-ray examination of the stomach before and after recovery from hypoproteinemia. The initial X-ray film on Nov. 2, 1990 (a) demonstrates giant folds in the body of the stomach. An X-ray film 4 months later (b) appears normal, and giant folds are no longer observed.

formed. The biopsy specimen displayed neither massive necrosis nor fibrosis and was compatible with the recovery phase of acute hepatitis. As these findings suggested protein loss from the GI tract as a cause of the hypoproteinemia, upper GI and half-life of serum albumin were examined. X-ray examination of the stomach showed enlarged tortuous folds in the fundus and corpus and the presence of a large amount of mucus (Fig. 2-a). Marked folding of the mucosa was confirmed at gastroscopy. Giant folds were most prominent along the greater curvature in the fundus and corpus (Fig. 3-a); these did not disappear in response to air insufflation. Although no such mucosal folds were evident in the pyloric antrum, there were several polypoid lesions accompanied by mucosal erosion, which had similar appearance to the crest of the thickened folds. The duodenal mucosa
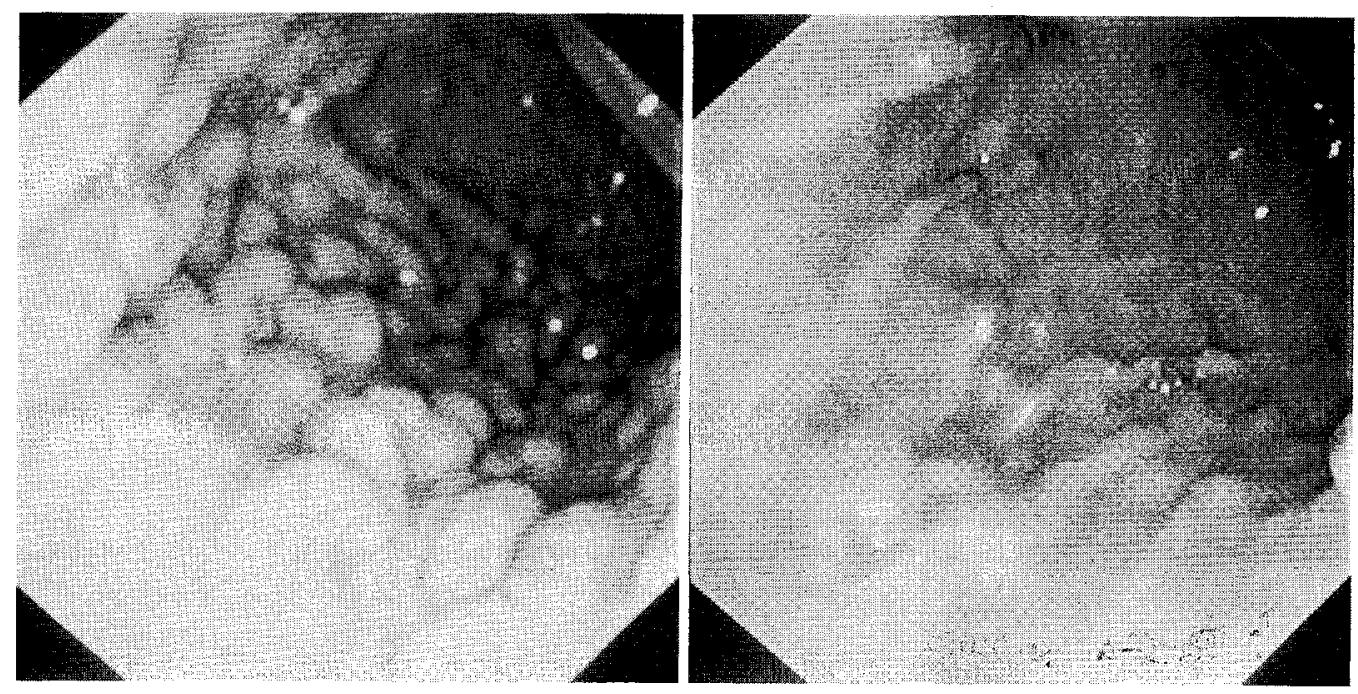

Fig. 3. Endoscopic appearance of the gastric mucosa. a) Initial examination on Nov. 9, 1990. Tortuous cnlarged gastric folds are observed. b) Follow-up examination on Jan. 25, 1991 shows normal gastric mucosa. 


\section{Hepatitis with Protein-losing Gastritis}

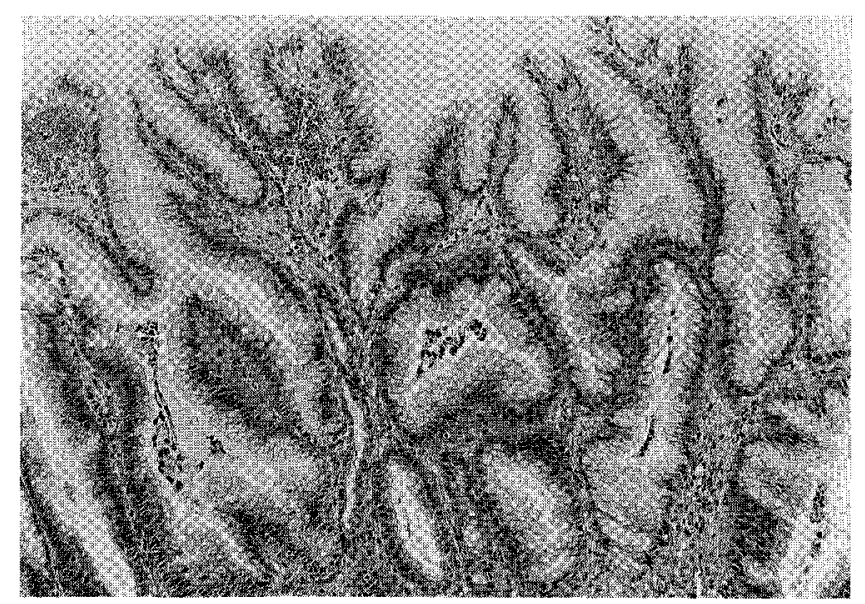

Fig. 4. Biopsy specimen from a gastric fold in the corpus shows hyperplastic changes in the foveolar cpithelium (hematoxylin and $\operatorname{cosin} \times 180$ ).

appeared normal. Biopsy specimens from both the gastric body (Fig. 4) and antral polypoid lesions revealed hyperplasia of the foveolar epithelium. Serum albumin half-life, determined using ${ }^{131}$ I-radioiodinated serum albumin, was 4.8 days, significantly shorter than the reported normal value of $12.1 \pm 0.5$ days (2).

Two months after admission, the patient's serum transaminase values returned to normal. Since he was completely free of symptoms at that time, he was discharged and followed up as an outpatient without any specific treatment. Regular laboratory studies showed continuous recovery of his hypoproteinemia (Fig. 1) with the serum protein level returning to within the normal range 2 months after discharge. At that point the upper GI study was repeated. Both X-ray and endoscopic examination showed complete disappearance of the gastric lesions (Fig. 2-b and Fig. 3-b). During the course of his disease, CF antibody titers against CMV decreased from 1:256 to $1: 32$ (Fig. 1, bottom), whereas antibody titers against EB-VCA and Toxoplasma did not significantly change.

\section{Discussion}

Many cases of giant hypertrophic gastritis accompanied by protein loss from the GI tract have been reported since first described by Ménétrier. It is regarded as a chronic disease in adults, and only a few cases of spontaneous regression have been reported $(3,4)$. In childhood, on the other hand, Ménétrier's disease has been described as pursuing a benign course, and an association with $\mathrm{CMV}$ infection has been documented $(5,6)$.

In the present case mild hypoproteinemia was present at the patient's first visit. We initially considered the possibility that the gastric giant folds and protein loss were longstanding and that the incidental development of acute hepatitis had aggravated the hypoproteinemia. Four months later, however, the patient had completely recovered from both the hypoproteinemia and gastric lesions. This clinical course suggests that his proteinlosing gastropathy had developed acutely and that the pathogenesis of the gastric lesions and the hepatitis were probably related. A similar case of protein-losing gastroenteropathy accompanied by hepatitis was reported by Mahmoud and McKechnie (7). As in acute hepatitis, our patient's course appeared to be atypical in two respects, i.e., a sore throat with low-grade fever preceded the onset of hepatitis by more than 3 weeks, and the rise in transaminase levels was extremely slow.

It should be noted that the patient initially had a high antibody titer against CMV and that the titer declined gradually during the course of his illness (from 1:256 to $1: 32$ ). Since we did not measure the IgM-antibody titer and did not find inclusion bodies in the biopsy specimens of the liver or gastric mucosa, there is no absolute proof of acute CMV infection. Nevertheless, the following considerations suggest a possible relationship with CMV infection in this case. 1) Ménétier's disease in childhood is usually benign and is reportedly associated with CMV infection. 2) The patient had signs of viral infection, such as lymphadenopathy and lymphocytosis, but serological tests had eliminated acute infection with hepatitis $\mathrm{A}, \mathrm{B}, \mathrm{C}$ virus or $\mathrm{EB}$ virus. 3) $\mathrm{CMV}$ is known to cause hepatitis as well as gastric ulcers (8). The etiology of giant hypertrophic gastritis, or Ménétrier's disease, is currently unknown, and because of the presence of transient and chronic forms, it may be diverse. The present case strongly suggests that one etiology is viral infection.

\section{References}

1) Ménétrier $P$. Des Polyadenomatoses gastriques et de leurs rapport avec le cancer de l'estomac. Arch Physiol Norm Pathol 32: 236, 1988 (in French).

2) Asakura $H$, Matsuzaki S. Study on serum albumin dynamic metabolism in digestive diseases. Keio Igaku 47: 143, 1970 (In Japanese).

3) Krol TC, Isenberg JI. Remission in a patient with Menetrier's disease: Spontaneous or induced by treatment? J Clin Gastroenterol 7: 161, 1985.

4) Frank BW, Kern F. Menetrier's disease. Spontaneous metamorphosis of giant hypertrophy of the gastric mucosa to atrophic gastritis. Gastroenterology 53: 953, 1967.

5) Coad NAG, Shah KJ. Menetrier's disease in childhood associated with cytomegalovirus infection: A case report and review of the literature. Br J Radiol 59: 615, 1986.

6) Oderda G, Cinti S, Cangiotti AM, Forni M, Ansaldi N. Increased tight junction width in two children with Ménétrier's disease. J Pediatr Gastroenterol Nutr 11: 123, 1990.

7) Mahmoud J, McKechnie J. Acute transient protein-losing gastroenteropathy in an adult. Am J Gastroenterol 57: 416, 1972.

8) Arnar DO, Gudmundsson G, Theodors A, Valtysson G, Sigfusson A, Jonasson JG. Primary cytomegalovirus infection and gastric ulcers in normal host. Dig Dis Sci 36: 108, 1991. 